\title{
Detection of human papillomavirus types in balanitis xerotica obliterans and other penile conditions
}

\author{
P W Y Lau, N Cook, H Andrews, A Bracka, S H Myint
}

\begin{abstract}
Objectives-To determine the prevalence of human papillomavirus (HPV) types 6, 11,16 and 18 in foreskin biopsies from patients with balanitis xerotica obliterans (BXO) and other penile conditions. Materials and methods-Foreskin biopsy specimens from 24 patients with penile lesions and 5 control patients were analysed by type-specific polymerase chain reaction (PCR).

Results-HPV6 or HPV16 were not detected in patients with BXO. HPV6 was detected in 2 controls.

Conclusions-Genital papillomaviruses do not have a strong association with BXO.
\end{abstract}

(Genitourin Med 1995;71:228-230) Keywords: Balanitis xerotica obliterans;
Papillomavirus

\section{Introduction}

Balanitis xerotica obliterans (BXO), also known as lichen sclerosis of the penis is an unusual condition that predominantly affects young adults and children. It is first manifest as white atrophic patches which may be mildly itchy. The plaques form bands which will eventually start to constrict the penis. The patient may suffer recurrent episodes of balanitis and eventually circumcision is often necessary. ${ }^{1}$ Squamous cell carcinoma has also been reported as a rare complication of the condition. ${ }^{23}$ The aetiology of this condition is unknown although genetic, autoimmune, hormonal and infectious mechanisms have been proposed. ${ }^{4}$ The search for a possible infectious agent has led us to examine the presence of known genital viruses in this condition. We present in this paper the results of screening for specific genital papillomaviruses, a possibility raised by the association of these viruses with squamous carcinoma.

\section{Materials and methods}

Materials Foreskin biopsy specimens had been collected between September 1991 and March 1992 from 10 patients with a clinical and/or histological diagnosis of BXO presenting to a genitourinary unit in Birmingham. Referral was from the entire unit and had been for circumcision. The specimens had been stored in formol-saline at $-20^{\circ} \mathrm{C}$. Biopsy specimens from patients with other penile skin disorders were collected over the same period. Five "normal" foreskins from adult patients undergoing routine circumcision for religious reasons were obtained from Leicester as control tissue.

$D N A$ extraction Approximately $2 \mathrm{~mm}^{3}$ of tissue was cut from each biopsy using a sterile scalpel. This was suspended in $1 \mathrm{ml}$ phosphate-buffered saline and freeze-thawed three times. After centrifugation at low speed $(7000$ $g$ ) the supernatant was discarded. The pellet was then homogenised in $1 \mathrm{ml}$ of tissue digestion buffer (100 mM NaCl, $25 \mathrm{mM}$ EDTA, $0.5 \%$ sodium dodecyl sulphate, $10 \mathrm{mM}$ Tris$\mathrm{HCl}$ pH 8) using a sterile mortar and pestle. The homogenate was then transferred to a 1.5 $\mathrm{ml}$ Eppendorf tube and digested with $10 \mu \mathrm{l}$ of proteinase $\mathrm{K}(20 \mathrm{mg} / \mathrm{ml})$ at $37^{\circ} \mathrm{C}$. Digestion was allowed to proceed until particulate material was not macroscopically visible. This was usually overnight but could take up to 5 days; which would require the addition of fresh proteinase $\mathrm{K}$ at 24 hour intervals. The digested material was then extracted once with chloroform:isoamylalcohol (ratio 24:1) and nucleic acid precipitated in $100 \%$ ethanol at $4^{\circ} \mathrm{C}$. After centrifugation the nucleic acid pellet was resuspended in $100 \mu \mathrm{l}$ sterile water for amplification by polymerase chain reaction (PCR).

\section{Polymerase chain reaction}

Human papillomavirus (HPV)-specifc PCR Oligonucleotide primers were synthesised from published sequences for HPV types 6, 11,16 and $18 . .^{5}$ These sequences were derived from the E6 region and are shown in table 1.
Department of Urology, Birmingham General Hospital, Birmingham B4 6NH, UK

H Andrews*

A Bracka

^Department of Sexual Health, Wellington Hospital, Wellington South, New Zealand

Correspondence to: Professor S H Myint. Accepted for publication 1 April 1995
Table 1 Oligonucleotide primer sequences used in the PCR amplification (from reference 5). All primers are annotated with reference to Genbank sequences and are written in a 5' to 3'orientation

\begin{tabular}{lll}
\hline HPV type & 5' Primer & 3' Primer \\
\hline HPV 6 & TCT ATC TAT GCA TAC GTT GC & CCA TTT TGT ATA TGA TTG GT \\
HPV11 & TCT TTC TTT GCA CAC TCT GC & GAA GTA TT TGA TT ATT GG \\
HPV16 & CAG GAC CCA CAG GAC CGA CC & CCC AGC CAC CTG GCC AGC TA \\
HPV18 & GCT TTG AGG ATC CAA CAC GG & GGT CAC GGT AAG CAC GAC GT \\
\hline
\end{tabular}


Figure $1 \quad P C R$ amplification of HPV6 sequences from patients with penile lesions.

Molecular weight markers (1kb ladder) is shown in lane 1 , lane 8 is a positive specimen (specimen 10) and lane 16 a positive control (HPV6 plasmid). Lanes 3-7 and 9-14 are negative specimens. $A$ negative control is present in lane 17.

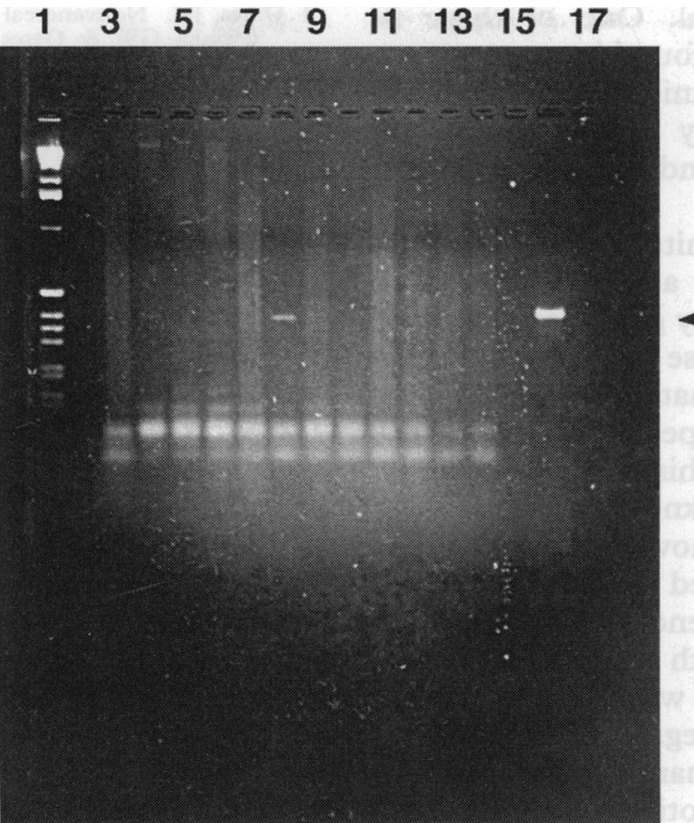

Extracted DNA $(0.5 \mu \mathrm{l})$ was amplified using the appropriate primers in an Amplitaq assay (Perkin-Elmer, Norwalk, USA) using the recommended buffer and reagent concentrations, and 5 units of Amplitaq polymerase. Appropriate positive controls, consisting of HPV insertion sequences derived from plasmids (kindly supplied by Professor E M de Villiers of the DeutschesKrebsForschungZentrum, Heidelberg) were used in all amplification runs. A negative control, sterile water, was also included and precautions were taken to minimise the risks of DNA carryover. After an initial "hot-start" of $94^{\circ} \mathrm{C}$ for 10 minutes, different cycling parameters were used for specific virus types. For amplification of HPV6 and HPV11 sequences, thirty cycles of $95^{\circ} \mathrm{C}$ for 30 seconds, $58^{\circ} \mathrm{C}$ for 30 seconds and $72^{\circ} \mathrm{C}$ for one minute were followed by a final extension at $72^{\circ} \mathrm{C}$ for 10 minutes. For amplification of HPV16 and HPV18 sequences the

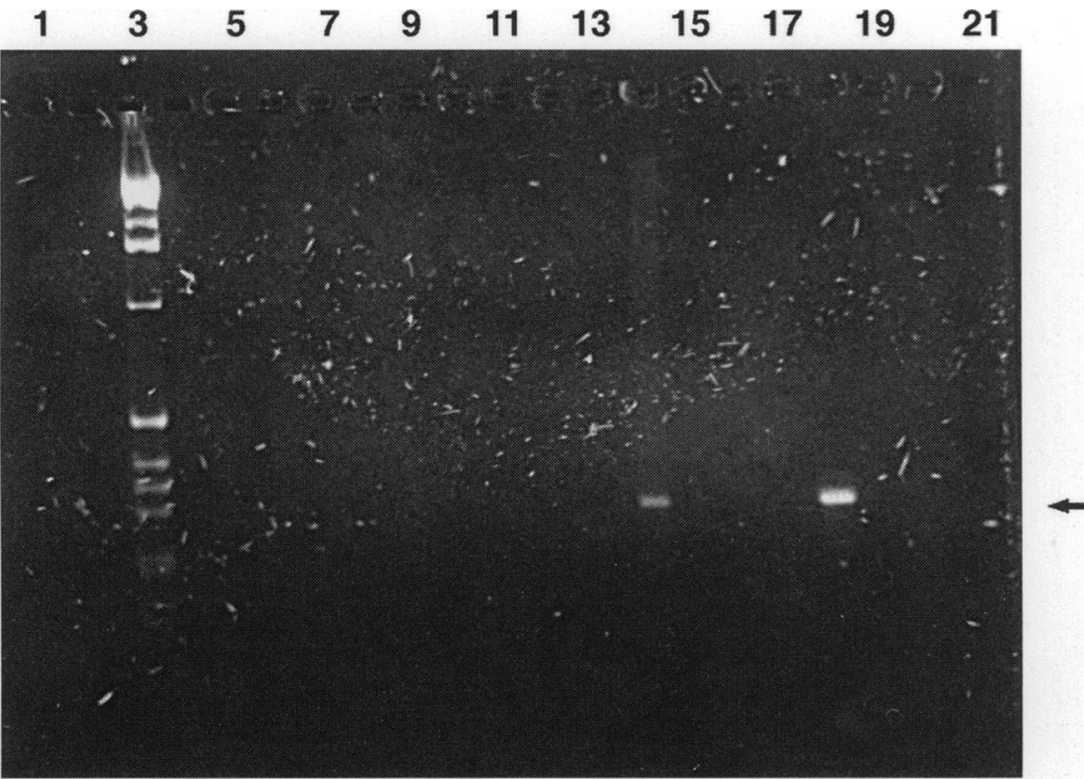

Figure 2 The results of PCR amplification of HPV16 sequences from 12 samples from patients with penile lesions. Molecular weight markers (1kb ladder), are shown in lane 3, lanes 4-13 and 15 are negative specimens, lane 14 (specimen 18) a positive specimen. $A$ positive control is shown in lane 18 , a negative in lane 1.
Table 2 Histological diagnoses and HPV types in 24 patients with penile conditions. Specimens that were not typed were positive by the HPV-general PCR but not by type-specific PCR

\begin{tabular}{rll}
\hline $\begin{array}{l}\text { Patient } \\
\text { number }\end{array}$ & Histological diagnosis & HPV type \\
\hline 1 & No diagnosis available & No HPV \\
2 & Balanitis xerosis obliterans & No HPV \\
3 & Balanitis xerosis obliterans & No HPV \\
4 & Non-specific balanitis & No HPV \\
5 & Balanitis xerosis obliterans & No HPV \\
6 & Genital warts & HPV not typed \\
7 & Balanitis xerosis obliterans & No HPV \\
8 & No diagnosis available & No HPV \\
9 & Non-specific inflammation & No HPV \\
10 & Genital warts & HPV6 \\
11 & Balanitis xerosis obliterans & No HPV \\
12 & Balanitis xerosis obliterans & No HPV \\
13 & Herpesvirus infection & No HPV \\
14 & Non-specific infection & No HPV \\
15 & Genital warts & HPV not-typed \\
16 & Balanitis xerosis obliterans & No HPV \\
17 & Bowenoid papulosis & No HPV \\
18 & Non-specific inflammation & HPV16 \\
19 & Balanitis xerosis obliterans & No HPV \\
20 & Non-specific inflammation & No HPV \\
21 & Balanitis xerosis obliterans & No HPV \\
22 & Non-specific inflammation & No HPV \\
23 & Balanitis xerosis obliterans & No HPV \\
\hline
\end{tabular}

thermal cycling protocol was thirty cycles of $95^{\circ} \mathrm{C}$ for 30 seconds, $68^{\circ} \mathrm{C}$ for 30 seconds and $72^{\circ} \mathrm{C}$ for one minute, with a final extension at $72^{\circ} \mathrm{C}$ for 10 minutes. All amplifications were undertaken in a Geneamp 9600 cycler (Perkin-Elmer, Norwalk, USA). Amplification products were visualised by electrophoresis in $2 \%$ agarose gels and ethidium bromide staining with ultraviolet illumination.

HPV general PCR Biopsy specimens that were negative by HPV-specific PCR were subjected to a PCR amplification with primers that would hybridise to sequences in most HPV types (though not HPV16). ${ }^{6}$

All specimens were subjected to amplification of $\beta$-globin genes using standard primer sequences. ${ }^{7}$

\section{Results}

Figures 1 and 2 show the results of positive (typeable) specimens. All the specimens were $\beta$-globin PCR positive. Table 2 summarises the results and histological diagnoses. It can be seen that none of the BXO specimens had detectable HPV sequences. The genital warts had detectable HPV as might be expected but interestingly only one was a common genital type. One of the cases of non-specific inflammation had detectable HPV but without follow up clinical information we cannot assess any pathological significance. Two of the five control specimens were positive for HPV6 only (data not shown).

\section{Discussion}

The evidence for an infectious aetiology for BXO is predominantly anecdotal. There is some support for the hypothesis, however, from studies that suggest there is chronic antigen stimulation in the disease. ${ }^{8}$ The association with squamous carcinoma might suggest an agent that had oncogenic potential. Much evidence has accumulated that specific HPV 
types have this potential. One of these is HPV 16 but this was not found in our patients using a very sensitive technique. The numbers are small but statistically the prevalence of HPV types in the BXO and non-BXO groups is different $(p<0.05)$.

The prevalence of genital human papillomavirus infections in the adult male population is not known with any great precision but studies in a subset, those that are sexually active have suggested that between 20 and $45 \%$ of men would be expected to carry genital papillomaviruses. ${ }^{910}$ This figure is higher in contacts of women with known cervical HPV infection. ${ }^{11} \mathrm{We}$ do not know the sexual histories of the patients enrolled in this study but it is clear that the prevalence in our control patients is consistent with other studies but the prevalence in patients with BXO is significantly less. This would negate a significant or consistent role for human genital papillomaviruses in balanitis xerotica obliterans. The search for an infectious agent should continue.

This work was supported in part by a grant from the Leverhulme Trust.
1 Oates JK. Nonvenereal disorders of the genitalia. In: Csonka GW \& Oates JK (eds.), Sexually Transmitted Csonka GW \& Oates JK (eds.), Sexually

2 Pride HB, Miller OF, Tyler WB. Penile squamous cell carcinoma arising from balanitis xerotica obliterans. $\mathcal{F} \mathrm{Am}$ Acad Dermatol 1993;29:469-73.

3 Campus GV, Alia F, Bosincu L. Squamous cell carcinoma and lichen sclerosus et atrophicus of the prepuce. Plast Reconstr Surg 1992;89:962-4.

4 Feldmann $R$, Harms $M$. Lichen sclerosis et atrophicus. Hautarzt 1991;42:147-53.

5 Nuovo GJ, Darfler MM, Impraim CC, Bromley SE. Occurrence of multiple types of human papillomavirus in genital tract lesions. Analysis by in situ hybridization and the polymerase chain reaction. Am $¥$ Pathol 1991; 138:53-8.

6 Datta C, Dutta SK, Chaudhuri A. Histopathological and mmunological studies in a cohort of balanitis xerotic obliterans. F Indian Med Assoc 1993;91:146-8.

7 Snijders PJF, van den Brule AJC, Schrijnemaker HFJ, Snow G, Meijer CJLM, Walboomers JMM. The use of general primers in the polymerase chain reaction permits the detection of a broad spectrum of human papillomavirus genotypes. $f$ Gen Virol 1990;71:173-81.

8 Saiki RK, Scharf S, Faloona F, et al. Enzymatic amplification of beta-globin genomic sequences and restriction site analysis for diagnosis of sickle cell anaemia. Science 1985;230:1350-4.

9 Hippelainen M, Yliskowski M, Saarikoski S, Syrjanen S, Syrjanen K. Genital human papillomavirus lesions of the male sexual partners: the diagnostic accuracy of penismale sexual partners: the diagnostic

10 Green J, Monteiro E, Bolton VN, Sanders P, Gibson PE. Detection of human papillomavirus DNA by PCR in semen from patients with and without penile warts. Genitourin Med 1991;67:207-10.

11 Schneider A, Hirchmayr R, De Villiers EM, Gissman L Subclinical human papillomavirus infections in male sexual partners of female carriers. $F$ Urol 1988;140 $1431-4$. 